\title{
Group Knowledge, Questions, And the Division of Epistemic Labour
}

\author{
JOSHUA HABGOOD-COOTE \\ Department of Philosophy, University of Bristol
}

\begin{abstract}
Discussions of group knowledge typically focus on whether a group's knowledge that $p$ reduces to group members' knowledge that $p$. Drawing on the cumulative reading of collective knowledge ascriptions and considerations about the importance of the division of epistemic labour, I argue for what I call the Fragmented Knowledge account, which allows for more complex relations between individual and collective knowledge. According to this account, a group can know an answer to a question in virtue of members of the group knowing parts of that answer, when the whole answer is available to group-level action. I argue that this account explains a swathe of central cases of group knowledge, as well as explaining some central features of group knowledge.
\end{abstract}

\section{Introduction}

What is the relationship between the knowledge had by a group, and the knowledge had by people who make up a group? Recent debates in social epistemology have focused on the question of whether a group's knowing something requires some member of that group knowing or believing it. ${ }^{1}$ This debate assumes that if there is an interesting relation between individual and group knowledge, it holds between individual and group-level attitudes to the same proposition.

In this paper, I develop an account of group knowledge that allows for a more complicated relation between individual and group knowledge. This picture is motivated by consideration of cases involving the division of epistemic labour, whereby a group deals with a complex body of information by dividing

1. See Hardwig (1985), Kitcher (1991), Thagard (1997), Tuomela (2004), List (2005), Wray (2007), Rolin (2007), Bird (2010; 2014), Fagan (2011; 2012; 2014), de Ridder (2014), Lackey (2014), Miller (2015), Klausen (2015).

Contact: Joshua Habgood-Coote <josh.habgood-coote@bristol.ac.uk> 
it into parts and assigning those parts to different members. ${ }^{2}$ This account involves two ideas: i) that a group can know an answer to a question in virtue of its members knowing various parts of that answer, and ii) that group knowledge requires that what is known is accessible to collective action. The full account combines distributed knowledge of the parts of an answer to a question with a requirement that this knowledge is accessible to group-level action, giving us the following account of group knowledge:

FRAGMENTED KNOWLEDGE: A group knows an answer to a question when individual members of that group between them know a set of partial answers which combine to yield that answer to the question and that answer answer is available to group-level action. ${ }^{3}$

I intend this account as a sufficient condition for group knowledge, but I don't want commit to the corresponding necessity claim. Group mentality and our talk and thought about collective entities are complex topics, and there may well be several different ways in which we might explicate the concept of group knowledge (de Ridder 2019) which might be useful for different purposes, or for different kinds of groups. In part, my project is ameliorative: I hope to make the case that the Fragmented Knowledge account provides a productive and useful way to think about the epistemic lives of various different kinds of groups. ${ }^{4}$ In particular, I argue that this account is well-suited for making sense of the knowledge had by groups with developed internal structures and procedures, 5 that it makes sense of the way we use collective knowledge ascriptions to explain and predict collective actions, and that it makes plausible predictions about the epistemic permissibility of collective actions and intentions.

The plan of action is as follows. In Section 2 I lay out the core cases of the division of epistemic labour, and in Section 3 I argue that none of the established accounts of group knowledge can make sense of these cases. In Section 4 I lay out a framework for thinking about questions, focusing on their part-whole structure, and in Section

2. For classic discussions of the division of practical labour, see Smith (1776/1982) and Durkheim (1893/2014). Modern literature typically uses the phrase 'the division of epistemic labour' to refer to a Smithian phenomenon of scientific competition (Kitcher 1990; Strevens 2003; Weisberg 2010; Weisberg \& Muldoon 2009; Zollman 2010), or to refer to a kind of epistemic dependence (Goldberg 2011). I will use the phrase to refer to the phenomenon in Smith's original example: cooperation within a team with diverse skills (see Muldoon 2017).

3. See Boddy (2014), Baltag, Boddy, and Smets (2018) for discussions of group knowledge that employ similar formal tools.

4. Throughout, 'group' and 'collective' will be used equivalently as umbrella terms for any agent partly or completely composed of individual agents.

5. In Section 6.4 I will consider unstructured groups, suggesting that although they cannot have fully-fledged collective knowledge, they can have collective propositional justification. 
5 I show how tools from this framework help us to think about the division of epistemic labour. In Section 6, I use these tools to formulate the Fragmented Knowledge account, starting with a simple account that looks to individuals' partial knowledge, before motivating the requirement that the answer proposition derived from individual knowledge be available to collective action. In closing we consider some upshots of the account and respond to some potential worries.

A couple of clarificatory points.

For presentational purposes I will be assuming that both knowledge-wh, and knowledge-how involve knowing propositions. There is a lively debate about the propositionality of knowledge-wh and knowledge-how (Bengson \& Moffett 2011b; Cath 2019; Fantl 2008; Parent 2014). Although a propositional picture of knowledge-wh has fairly wide support, a propositional picture of knowledgehow is extremely controversial. Taking on the assumption of propositionality massively simplifies our presentation, allowing us to use the same machinery to make sense of the division of labour involved in knowledge-that, knowledgewh, and knowledge-how. However, this assumption is not required for the success of the Fragmented Knowledge account. The central claim of this account concerns the relation between individual and group-level knowledge, meaning that it is neutral on how to understand individual knowledge. The core idea of this account is that a group can know something in virtue of its members knowing the parts of that thing. This idea can be filled out in different ways depending on how we understand knowledge, the kinds of things that we can know, and the different kinds of part-whole structures had by the objects of knowledge. ${ }^{6}$

The inspiration for the Fragmented Knowledge account comes from discussions of what linguists call the cumulative-or sometimes the semi-distributivereading of collective knowledge-wh ascriptions. In fact, our first pass at an account of collective knowledge (FRAGMENTED KNOWLEDGE 1) is extremely close to Uptal Lahiri's (2002: C4) semantics for this reading. The fact that the account takes inspiration from formal semantics raises the difficult question of the proper relation between ontology and formal semantics. This question has been discussed both in relation to knowledge-how (Devitt 2011; Glick 2011; Noë 2005; Stanley 2011; Stanley \& Williamson 2001), and social ontology (Ritchie 2016; in press). Some authors seem to treat linguistic evidence as providing conclusive answers to philosophical questions, taking what Devitt (2011) calls a linguisticsfirst approach. We don't need to rely on this methodology to make use of linguistic evidence in philosophy. The Fragmented Knowledge account certainly takes inspiration from semantics, but I think that it should be assessed on the

6. See Section 6.6 for a discussion of how this account might be tweaked for a non-propositional account of knowledge-how. 
basis of both linguistic and philosophical considerations.7

\section{The Division of Epistemic Labour}

In this section, I set out three cases in which a group possesses knowledge in virtue of knowledge distributed among its members. ${ }^{8}$ These are divergence cases, in the sense that the groups in these examples each know propositions which none of their members do. The three cases I consider cover different kinds of knowledge (how, wh, and that) and, as we shall see in Section 5, provide examples of different ways in which answers to sub-questions can combine.

Our first case comes from Bird (2010: 33-34) with some details added:

NASA: NASA has formed a plan to build a space shuttle. This is a complicated process, involving a number of tasks which draw on specialised knowledge. In order to build the shuttle efficiently the planning committee splits the task into various sub-tasks and assigns specialists to each of these tasks. A programmer is assigned to design the software; a chemist to make up the fuel; an aeronautical engineer to build the fuselage; and so on. Each of the specialists has a good deal of knowledge about how to perform their task but none of them has any knowledge about any of the other sub-tasks. Nonetheless, the team of specialists does an excellent job, and the space shuttle is successfully made.

In this case, sentences 1) and 2) both seem true:

1) NASA knows how to make a space shuttle.

2) No-one in NASA knows how to make a space shuttle.

This pair of judgements is intuitively plausible and is backed up by surveys of non-philosophers' intuitions (Jenkins, Dodell-Feder, Saxe, \& Knobe 2014). ${ }^{9}$

7. For an argument for this attitude toward linguistic evidence in the knowledge-how debate, see Habgood-Coote (2018b).

8. For cases with similar structures, see Tollefsen's UN population case (Tollefsen 2007; Lackey 2012; 2014), Bird's interdisciplinary modus ponens case (Bird 2010: 34-35), Hutchins's (1995) discussion of the USS Palau, Knorr Cetina's (1999) discussion of the high-energy physics community, and the cases of radical collaboration in Kukla (2012), Winsberg, Huebner, and Kukla (2014), Huebner, Kukla, and Winsberg (2017).

9. Jenkins et al (2014) presented 116 participants with a case like NASA, and considered whether participants ascribed knowledge to the group, and to its members. Although they don't report results specifically for this case, we can isolate responses to this case, and run the same tests as they do. A one-way ANOVA revealed a significant effect of question condition on responses for 
Our second case involves knowledge-who:

PARTY: The members of the Rowing Club are hosting a party in their clubhouse and have decided that each member of the club will stay in one of the rooms in the club-house for the whole night to ensure that none of the rooms gets trashed. Each person who visited the party visits at least one of the rooms and introduces themselves to the club-member in that room, but none of the rooms was visited by all the partygoers. Each of the club members has an excellent memory and remembers the names of everyone who they met.

This case supports a similar pair of divergent judgements, expressed by 3) and 4):

3) The Rowing Club knows who came to the party.

4) None of the members of the Rowing Club knows who came to the party.

Our third case is adapted from an example that comes from Roger Schwartzschild via Uptal Lahiri (2002: 189-190), and involves both knowledge-whether and knowledge-that:

LITTER: The members of a scout group are carrying out a project about littering, and have decided to investigate whether there is any litter on a local bike path. The path is a couple of miles long, so the group splits up, with each member searching one section of the path, noting down if they see any rubbish. In fact the path is litter-free, and each of the scouts searches their part of the path in vain.

In this case, we can formulate divergence judgements using both knowledgewhether and knowledge-that. Consider the following pairs of sentences uttered at a time between the information having been gathered and everyone reporting their results (by which time everyone would know that the path was litter-free):

this single case, $\mathrm{F}(2,115)=97.81, \mathrm{p}<.001, \eta^{2}=.63$. Tukey's posthoc tests showed that on a 1 to 7 scale ( 1 low, 7 high) participants agreed more with ascriptions in the group-level condition (condition two, which is equivalent to sentence 1$)(M=6.48, S D=1.24)$ than in either the 'each member' question condition (condition three) $(\mathrm{M}=1.68, \mathrm{SD}=1.19), \mathrm{p}<.001$, or the 'any member' question condition (condition one, which is equivalent to the negation of sentence 2$)(\mathrm{M}=3.10, \mathrm{SD}=2.07), \mathrm{p}$ $<$.001. This suggests that in cases like NASA the folk are willing to ascribe knowledge to the group, while not ascribing knowledge to its members. 
5) The scouts know whether the whole path is litter-free.

6) None of the scouts knows whether the whole path is litter free.

7) The scouts know that the path is litter-free.

8) None of the scouts know that the whole path is litter-free. ${ }^{10}$

As a group, the scouts seem to have knowledge-whether and knowledgethat which goes beyond that possessed by any individual scout.

I suggest that we should take the divergence judgements in NASA, PARTY, and LITTER seriously. Although we do sometimes mistakenly ascribe knowledge to groups when the groups are really just in a position to know the propositions in question (Lackey 2014: 294-295), considerations of the explanatory and normative role of knowledge supports the claim that these are genuine cases of collective knowledge.

Sentences 1), 3), 5), and 7) predict and explain the actions of the groups in the ways distinctive of knowledge. We might appeal to NAsA's know-how to predict that it will successfully make a shuttle, or appeal to the scout group's knowledge about whether the path is litter free to predict whether it will keep scouring the path. These sentences can also be used to flag the respective groups as informants (Craig 1990). If the police were rounding up partygoers, it would be natural for a police officer to say:

9) Let's get the Rowing Club in; they know who came to the party.

The ascriptions of knowledge to the groups also predict the appropriateness of collective action, assertion, and intention (Habgood-Coote 2018a; Hawthorne \& Stanley 2008; Williamson 2000). NASA could rationally form an intention to make a space shuttle, the Rowing Club would be acting with epistemic propriety if it gave a statement about who was at the party that drew on its members' knowledge, and the scout group would be acting with epistemic propriety if it claimed the council reward for having a litter-free cycle path on the basis of its members' knowledge. ${ }^{11}$

It is also difficult to take issue with the denial of knowledge to the members of the groups. In NASA we can truly say things like 'the chemist knows how to

10. One might take issue with the claim that the scouts know whether the path was litter free before they share their results. Until the results are announced, we might think that the group is merely in a position to know whether the path was litter-free (Lackey 2014). One might motivate this move by arguing group knowledge requires some kind of joint commitment to the proposition in question. Although there might be a perfectly good sense of collective knowledge has this requirement, the considerations about the explanatory and predictive roles of knowledge ascriptions below suggest that there is also a good sense in which the group does know the answer to this question before its members pool their results.

11. For the significance of the qualifications about the basis of action, see Section 6.7. 
make a space shuttle,' but only in a sense that expresses very coarse-grained and general knowledge (you have to build the fuselage, make fuel, and program the computers) which falls far short of the practical knowledge which we are supposing is possessed by the group. ${ }^{12}$ If we focus on the relatively demanding readings of the knowledge ascribed to the groups, it should be clear that the members of the group do not know what the group does.

What lessons might we draw from these cases?

The modest lesson is that these cases demonstrate the importance of what linguists call the cumulative reading of group knowledge ascriptions. Whereas a distributive reading of a predicate ascribes a property to each of the members of the group, and a collective reading ascribes the predicate to the group collectively, the cumulative reading claims that the members of the group contribute to the collective fulfilling the predicate such that between them the predicate fully obtains. ${ }^{13}$ When linguists discuss sentences like 1), 3), 5), and 7) they seem to have the modest lesson in mind.

The ambitious lesson is that these cases instantiate an important feature of collective knowledge: the division of epistemic labour. ${ }^{14}$ A central feature of collective agents is their ability to deal with complex tasks by splitting them into simpler tasks that can be performed more efficiently by individuals with the appropriate skills. For example, NASA can deal with the task of making a space shuttle by splitting it up into simpler tasks like making the fuselage and concocting the fuel. We might think this division of labour carries across into the epistemic realm, and that the cumulative reading of knowledge ascriptions picks out the kind of knowledge which is its consequence. This point is easiest to see in the case of collective

12. We get a similar phenomenon if we focus on the mention-some reading of 'who came to the party' in 4).

13. To get a grip on the cumulative reading, consider:

$\left.1^{\prime}\right)$ Four linguists wrote three books.

On the collective reading, the four linguists jointly wrote three books. On the distributive reading, each of the four linguists wrote three books. On the cumulative reading, there is some way to combine the linguists as authors or co-authors such that between them the number of books that they wrote is three (say, if three co-wrote one book, and the other the other two). For discussion of this reading in linguistics, see Scha (1981), Landman (1989), Gillon (1992), Schwarzschild (1996), Lahiri (2002: 184-220), and for discussions in philosophy see Dever (1991), Oliver and Smiley (2008), Linnebo and Nicolas (2008), Cotnoir (2013: 308-311), Ludwig (2016: ch. 10 note 25).

14. To make things simpler, I have focused on cases where the division of labour is formalized by the group's organizational structure. Cases where a division of labour is implemented in a less formal way - think of the invisible hand of the market (Hayek 1945), competition in science (Strevens 2003), or the contingencies of social position (Collins 2000) - will be much more complicated. These cases will potentially run afoul of the accessibility to collective action conditionpresumably the invisible hand acts only in a metaphorical sense-but we can still use the machinery of questions and subquestions to think about the epistemic potential of these groups (see Section 6.4). 
inquiry: a collective agent can perform the task of coming to know something by different members coming to know suitably related smaller things.

If we draw the modest lesson, what we want is an account of the kind of knowledge picked out by the cumulative reading of collective knowledge ascriptions, which we can treat as a linguistic curio. By contrast, if we draw the ambitious lesson, these cases demonstrate an important structural feature of collective knowledge which we will want to build into our account. I will draw the ambitious lesson, but if for some reason the general account of group knowledge turns out to be incorrect, then what I say below can be repurposed as an account of the cumulative reading of group knowledge ascriptions.

\section{Explaining the Division of Labour}

There are various accounts of group knowledge available in the literature. In this section I argue that none of them can offer an explanation of the division of epistemic labour exhibited in cases like NASA, PARTY, and LITTER.

A central question for accounts of group knowledge is whether they endorse the following principle:

SUMкNow: A group $G$ knows that $p$ only if at least one member of $G$ knows that $p$

Following convention, we can call accounts that endorse SUMкNow Summativist, and accounts that deny it Non-Summativist. ${ }^{15}$

Summativist accounts cannot explain the presence of group knowledge in NASA, PARTY, and LITTER. These are cases in which a group knows something which no member of the group knows. In fact, we could easily tweak NASA, PARTY, and LITTER so that no member of the group had any attitude toward the proposition known by the group. It wouldn't be particularly odd if the members of NASA had simply never considered how to make a space shuttle, having no view on the matter.

15. The question of whether SUMкNow holds is often associated with whether group knowledge is reducible to individual knowledge. The reducibility of group knowledge is orthogonal to the truth of SUMкNоw. One might endorse SUMкNow and deny the reduction of group to individual knowledge. For example, one might hold a mixed view that claims that both individual knowledge and some group-level phenomenon is necessary for collective knowledge (See (Lackey 2016) for an account of group justified belief with this structure). One might also deny SUMKNow whilst endorsing the reduction. For example, one might claim that group knowledge reduces to some individual-level attitude other than knowledge that $\mathrm{p}$. These points generalise to other group attitudes, meaning we should sharply distinguish between the questions of whether Summativism is true, and the question of whether group attitudes are reducible to individual attitudes. 
We can divide up non-Summativist accounts by considering which part of the knowledge is located at the collective level. This gives us the following menu of views to consider:

i) Group knowledge involves collective belief (Wray 2007);

ii) Group knowledge involves collective justification (de Ridder 2014; Lackey 2016);

iii) Group knowledge involves group-level reliability (List 2005);

iv) Group knowledge involves group-level realisation of functional properties (Bird 2010).

None of these accounts has a satisfying explanation of these cases.

Wray (2007) appeals to Margaret Gilbert's (1987) account of group belief, suggesting that the collective element of group knowledge is a joint commitment to the proposition known (although he argues that we should think of joint commitments as acceptances, not beliefs, see Wray 2001). This account can't handle NASA, PARTY, and LITTER, because the members of the groups in these cases need not be jointly committed to the propositions known by the group. As individuals, the members of NASA might not have any commitments about the best way to make a space shuttle. Although the rowing club and scouts might jointly commit to propositions after having shared their distributed information, these groups know the propositions in question before they pool their knowledge.

De Ridder (2014) argues that scientific knowledge is a collective property because scientific knowledge requires access to reasons for the reliability of belief-forming processes, and in contemporary science this understanding is often distributed between the specialists in a research team. Although this may be a plausible picture of what occurs in some cases of collective scientific knowledge, this diagnosis doesn't fit well with NASA, PARTY, and LITTER. These are cases in which the object of knowledge - rather than the reasons justifying it-is distributed between the members of the group. ${ }^{16}$

Lackey's (2016) group epistemic agent account of justified belief claims that a group justifiedly believes some proposition when it is believed by a significant number of operative members of the group, the bases of individual beliefs in that proposition are coherent, and a rational process of deliberation would lead to a belief set which still supported that proposition. Although this is an account of justified belief, rather than knowledge, it is worth considering whether it can be put to work here. The problem lies in the first condition: in NASA, PARTY, and LITTER no member of the group has a justified belief about the proposition

16. Note that the supporter of the Fragmented Knowledge account can treat de Ridder's cases as involving fragmented knowledge of the answer to the question why is this process reliable?. 
known by the group, meaning that Lackey's account predicts that none of these cases involve collective justified belief.

List (2005) develops a judgement aggregation approach to group knowledge. The core idea of this approach is that a group's institutional structure will determine an aggregation function that takes as inputs a profile of individual beliefs and outputs a collective position for that group (see List \& Pettit 2011). We can assess whether a group's collective position constitutes knowledge by considering how reliable the outputs of the aggregation function are, which will be a function of both individual reliability and the reliability of the aggregation function. List (2005: 29) considers an aggregation function tailor-made for situations involving a division of labour: the distributed premise-based procedure. This function splits a group into sub-groups whose attitudes determine the group's attitude on premises which are then combined to yield a collective position on the conclusion (see also List \& Pettit 2011: $\mathrm{C}_{4}$ ). The problem with applying the judgement aggregation approach to understand distributed knowledge is that a group can possess distributed knowledge, even if its institutional structure fails to implement the right aggregation function to exploit this knowledge. Goldman (2004) cites an exchange from the 9/11 commission hearings which illustrates the way a group's aggregation function can diverge from its knowledge. Commenting on why the FBI did not internally share information about the 9/11 perpetrators' flight training, former national security advisor Samuel Berger made the following Rumsfeldian pronouncement:

We've learned since 9/11 that not only did we [the FBI] not know what we didn't know, but the F.B.I didn't know what it did know. ${ }^{17}$

The force of this remark is that although the FBI's aggregation function was faulty-meaning that it was not able reach the right position about whether the perpetrators were a threat - the distributed knowledge possessed by FBI members still qualifies the group as having collective knowledge about this question. ${ }^{18}$

Bird (2010) pursues an analogical strategy, exploiting the idea that individual and collective knowledge will have the same functional properties. He argues

17. Full transcript: http://www.washingtonpost.com/wp-dyn/articles/A20349-2004Mar24. html??noredirect $=$ on

18. To muddy the waters, we can read 'the FBI didn't know what it did know' in two ways. The first reading is a denial of higher-order collective knowledge (i.e., the FBI was ignorant about the question of what it knew). The second reading is effectively a contradiction test exploiting the ambiguity of 'knows' (Zwicky \& Sadock 1975: 4). We can get fix this reading by using the following focus pattern: 'the FBI didn't [know $]_{\mathrm{f}}$ what it did know' (i.e., the FBI knew, but it didn't really know). We are interested in the first reading, according to which the FBI's higher-order ignorance prevented it from acting on its knowledge. 
that the characteristic properties of group knowledge are that it i) is produced by a social process which produces propositional outputs, ii) involves truth-filtering mechanisms, and iii) yields outputs which are available to social action and other social information-filtering processes. ${ }^{19}$ On this account, group knowledge is a state which lies causally downstream of social information-filtering processes, and which can at least potentially feed into other social processes. Fagan (2012) helpfully distinguishes between three senses of collective knowledge: knowledge that is collectively produced, knowledge involving a collective agent, and knowledge involving a collective content. Bird's account is well-suited to explain cases of collective production of knowledge, but it fails to generalise to all cases of knowledge involving a collective agent. ${ }^{20}$ In the cases under consideration the groups' knowledge need not be the output of a social information-filtering process. NASA might have assembled a group of people with the appropriate specialised knowledge, and it would still wind up knowing how to make a space shuttle.

Given the failure of extant accounts to make sense of NASA, PARTY, and LITTER, we will need to look elsewhere for an account of the division of epistemic labour. In the next section, I will gather the tools we need to think about these cases, before applying these tools in Section 5 .

\section{The Mereology of Questions}

Following Lahiri (2002: 188), I think that the right way to understand the cumulative reading of sentences like 1), 3), 5), and 7) is to think of them as ascribing partial knowledge to members of the group that adds up to a resolving answer to the question..$^{21}$ To develop this idea, we will need some tools from the semantics of interrogatives. In particular, we need to understand: i) what questions are, and how they relate to answers ii) partial knowledge-wh, iii) what it is for one

19. Although I am skeptical of conditions i) and ii) in Bird's account, the availability condition $\mathrm{FK}_{3}$ in FRAGMENTED KNOWLEDGE 2 is pretty close to iii).

20. Bird's central interest is in groups that manifest Durkheimian organic unity (see Bird 2014), suggesting that his account should be understood as an account of group knowledge for groups characterised by organic unity. Thus restricted, the worry for his account is that groups with a relevant organic unity - such as NASA-can come to know without undergoing a social process of learning.

21. For a similar idea, see Hardwig (1985: 349). For the details of Lahiri's semantics for the cumulative reading, see Lahiri (2002: $\mathrm{C}_{4}$ ), and for an alternative treatment which appeals to quantification over the parts of questions, see (Beck \& Sharvitt 2002: 149-52). Note that following Schwarzschild, Lahiri connects the cumulative reading to sentences involving verbs connecting two grammatically plural terms. This means that his account does not neatly carry over to sentences like 1) and 3) which involve grammatically singular noun phrases denoting a group agent (i.e., 'NASA', and 'the Rowing Club'). 
question to be part of another, and iv) the different ways in which the answers to several smaller questions can combine to resolve a bigger question. The subsections that follow address these questions in turn.

\subsection{Questions}

As I will use the term, a question is an entity which is denoted by a sentence or clause in the interrogative mood. The interrogative sentence 'who came to the party?' denotes the question who came to the party?, just as the declarative sentence 'Tariq came to the party' denotes the proposition Tariq came to the party (throughout I will use italics for questions, propositions, and predicates, and quotes for sentences and clauses). In the central case, an interrogative sentence or phrase is composed of a wh-word ('who', 'how', 'which' 'when', 'how', and so on) and a question abstract (such as 'came to the party'). In these cases, the wh-word functions as a variable with a domain restriction (for example 'who' restricts to people), and the question abstract expresses a predicate. ${ }^{22}$

Questions and propositions are closely related in that propositions answer questions. In the simplest case they do so by assigning elements in the domain to the extension of the predicate. For example, Tariq came to the party answers the question who came to the party? by assigning Tariq to the extension of came to the party.

One way to make sense of the relation between questions and propositions is to think that a question just is the set of propositions which are its potential answers (Hamblin 1958). There are various ways to build a question out of its answers (for an overview, see Roelofsen 2018). I will employ a possible worlds framework that understands a question as a partition over a set of possible worlds (this account is based on the presentation in Roberts 2012). Although this is not the only possible approach, it allows us to draw the distinctions we need in a perspicuous way without introducing too much background theory. ${ }^{23}$

This partition approach takes Hamblin's (1958) idea that a question is a set of propositions and identifies these propositions with the exhaustive answers favoured by Groenendijk and Stokhof (1982), meaning that a question is the set of its potential exhaustive answers (Higginbotham 1996; Roberts 2004; 2012). To get to an exhaustive answer, we take the domain suitably restricted by the wh word, and the question abstract, then build a possible assignment of all entities in the

22. We will need to complicate the picture to deal with interrogatives with multiple whwords, 'whether' interrogatives, and interrogatives with no question-words.

23. The distinctions we need would be rather difficult to draw in the alternative semantics proposed by Hamblin (1973) or Karttunen (1977). I think it would be possible to reconstruct them within an inquisitive semantics framework (Ciardelli, Groenendijk, \& Roelofsen 2015; 2018), but this would considerably complicate the presentation. 
domain to either the extension or the anti-extension of the predicate expressed by the question abstract. A question is the set of all of these exhaustive answers. Because each exhaustive answer is a maximal assignment of the entities to the predicate expressed by the question abstract, each one is incompatible with all of the others.

If we think about answer sets in a possible worlds framework, each exhaustive answer will be a set of worlds corresponding to a maximal assignment of the entities to the predicate expressed by the question abstract, and the question will be identical to the set of all of these sets of worlds. Because these exhaustive answers are incompatible, this set of sets will be a partition defined over the portion of logical space in which the presuppositions of the question are met (Lahiri 2002: 10; Masto 2010). Exactly one of these exhaustive answers will be a true proposition-assuming that the question has true presuppositions-the one corresponding to the cell containing the actual world.

This picture allows us to distinguish various different kinds of answer to a question. Borrowing terminology from Szabo (2017), let's call a proposition that assigns an entity to the extension of the predicate expressed by the question abstract a positive minimal answer (such as Tariq came to the party), and a proposition that assigns an entity to its anti-extension a negative minimal answer (for example, Paula didn't come to the party). A conjunction of positive minimal answers is a mention-some answer (for example, Tariq and Paula came to the party), and any combination of minimal answers with logical connectives is a partial answer (for example, if Tariq came, then Layla didn't come). The conjunction of positive minimal answers is a mention-all answer (for example, Tariq, Paula and Jerry came to the party, if these are all of the party-goers). The most informative answer is a complete set of positive and negative minimal answers to a question, which we will call a complete answer (for example, Tariq, Paula, and Jerry came to the party, and no-one else did). This kind of answer is often called an exhaustive or strongly exhaustive answer, since it involves both the complete list of positive answers, and the information that that list is complete. ${ }^{24}$

The partition framework allows us to think about these distinctions in terms of how many cells in the partition are ruled out by the different kinds of answers. Every potential complete answer will correspond to exactly one cell in the partition, meaning that knowing a complete answer allows one to rule out all but one of the cells in the partition. A mention-some answer won't necessarily isolate just one cell, but will isolate a set of cells at which some conjunction of positive minimal answers holds. Minimal answers allow one to rule out sets of cells in which the minimal positive or negative answering propositions are false. Partial

24. A complete answer will also be a mention-some answer, a mention-some answer will also be a partial answer, and a mention-some answer will either be or entail a positive minimal answer. Often, I will be implicitly adding a 'mere' before 'partial answer'. 
answers allow one to rule out a set of cells depending on the logical connective used: for example, if A came, then B came allows one to rule out the set of cells in which A came, but B did not come.

What kind of answer we are interested in will often depend on conversational context. ${ }^{25}$ If we want to find someone to ask about whether the party was good, a minimal positive answer to who came? will do, but if we want to write an oral history of the party, then we'll need a complete answer. Let's introduce the notion of a resolving answer, and say that in a conversational context an answer is resolving just in case it gives the interlocutors sufficient information to meet their informational needs with respect to that question..$^{26}$ In a context in which an interrogative phrase takes a mention-some reading, all that is required for a resolving answer is a mention-some answer, whereas in a case where an interrogative phrase takes a mention-all reading, only a complete answer to the question will count as resolving. The notion of a resolving answer is effectively a placeholder for a pragmatic theory of how a particular reading of the question is selected.

\subsection{Partial Knowledge}

The distinction between partial and resolving answers gives us a helpful tool for understanding the gradability of knowledge-wh ascriptions (Pavese 2017). A typical knowledge-wh ascription involves a verb with an unmodified interrogative complement. For example:

10) Maja knows which students are in detention.

This kind of sentence ascribes knowledge of a resolving answer to the question expressed by the complement, in this case a proposition specifying exactly which students are in detention. We also find knowledge-wh ascriptions involving adverbs of quantification modifying the interrogative complement. Consider the following example (with the adverbial phrase underlined): 27

25. On the context-sensitivity of the answerhood relation, see Boër and Lycan (1986).

26. It is somewhat of an idealisation to think that context always fixes which kind of answer is required. Does context always fix whether a mention-some or mention-all reading of an interrogative is intended, or fix a relevant domain of quantification? This means that some knowledge-wh ascriptions (including to groups) will have an indeterminate meaning.

27. Some examples with different verbs, adverbs, and question-words:

$1^{\prime \prime)}$ Dale has worked out in part how to make the wardrobe

$\left.2^{\prime \prime}\right)$ Patricia learnt for the most part who was at the party.

$\left.3^{\prime \prime}\right)$ John knows to some extent where the lost pages are. 
11) Maja knows in part which students are in detention.

If Paul, Jojo, and Trent are in detention, and Maja knows only that Paul and Jojo are in detention, then II) is true. Sentence 11) says that Maja knows a partial answer to which students are in detention?, and not that Maja has a state short of knowledge relating to a resolving answer to the question. The adverb modifies the

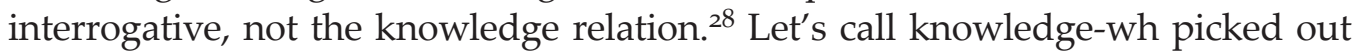
by ascriptions involving partial quantificational adverbs partial knowledge-wh. ${ }^{29}$

We can use the machinery of answers and partial answers to give accounts of both knowledge-wh and partial knowledge-wh. Here is a fairly standard propositional picture of knowledge-wh (along the lines of Higginbotham 1996):

KNOWS-WH: $S$ knows Wh-F? iff $S$ knows that $p$, and $p$ is a resolving answer to the question $W h-F$ ?.

The kind of answer appealed to here is a resolving answer, and not a complete answer. In the right context, knowing a mention-some answer (or even something weaker) can be sufficient for a true knowledge-wh ascription. This means that KNOWS-WH commits us to a contextualist semantics for knowledge-wh ascriptions. This view is different to the familiar contextualist accounts of knowledge-that in the sense that it is contextualist about the object of knowledge, rather than about the knowledge relation. ${ }^{30}$ It is what is known, rather than what knowledge is, that is determined by context.

This kind of gradability has been discussed in linguistics under the heading of Quantificational Variability Effects (QVE). See Berman (1991), Groenendijk and Stokhof (1993), Williams (2000), Lahiri (2002: chs. 2 and 5), Beck and Sharvitt (2002). For a philosophically illuminating application of some of these ideas to the debates about the gradability of 'knows-how' ascriptions and the unity of knowledge, see Pavese (2017), and Pavese (2015) respectively. Knowledge-wh ascriptions can also be modified by qualitative predicates, such as:

$\left.4^{\prime \prime}\right)$ Raimo knows how to swim really well.

These predicates seem to modify the entities expressed by the wh-word. What is good is the way of swimming that Raimo knows how to perform (Pavese 2017).

28. Because this kind of gradability involves modification of the interrogative complement rather than the verb, it is compatible with the claim that 'knows' is not a gradable verb (Pavese 2017; Stanley 2005).

29. There is considerable discussion about how to understand QVE. Accounts have been proposed that appeal to quantification is over i) the objects which the wh-word ranges over (Berman 1991), ii) propositional answers to the question (Lahiri 2002), iii) subquestions of the superquestion (Beck \& Sharvitt 2002), and iv) question-proposition pairs (Pavese 2017).

30. For defences of contextualism about knowledge-wh, see Boër and Lycan (1986), DeRose (2009: ch. 2 appendix), Masto (2010), Parent (2014). For a criticism appealing to warranted assertibility see Braun (2006; see also Hawley 2003). Strength of answer is just one of several kinds of context dependence involved in knowledge-wh ascriptions. The semantic content of interrogatives will probably also be affected by the domain of quantification (Stanley 2011: 56-58, 118), modulation of the predicate expressed by the question abstract, and the salient method of identification (Aloni 2008). Infinitival interrogatives will also involve context-sensitive modals (Bhatt 2006; Stan-

$$
\text { Ergo •vol. 6, no. 33 } 2020
$$


This account can be straightforwardly extended to deal with partial knowledge-wh by replacing resolving answers with partial answers:

PARTIAL KNOWS-WH: $S$ knows in part Wh-F? iff $S$ knows that $p$, and $p$ is a mere partial answer to the question $W h-F ?^{3^{1}}$

This is a schematic account, and it would have to be complicated to deal with the full range of quantificational modification involving different amounts of knowledge about an answer (see the examples in Footnote 27).

\subsection{Subquestions}

Another payoff of the partition approach is that it gives us a clear account of what it is for one question to be part of another (see Roberts 2004; 2012).

We can make a first pass at understanding question-parthood by saying that one question is part of another when it divides up the same portion of logical space, but with a smaller number of more coarse-grained cells. Consider the question who came to the party?. Assuming a domain of just $\mathrm{A}$ and $\mathrm{B}$, this question gives us the following partition of four cells (where ' $\mathrm{A}$ ' stands for $A$ came to the party, and 'a' stands for $A$ didn't come to the party):
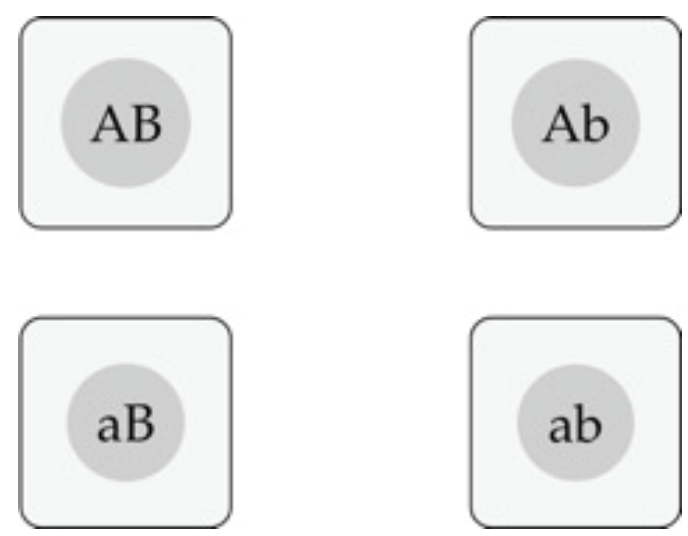

Figure 1. Who came to the party?

\footnotetext{
ley 2011: 126), contextual resolution of the reference of PRO (Stanley 2011: $C_{3}$ ), and may involve an unpronounced task variables (Hawley 2003: 21-22).

31. This account is slightly oversimplified for presentational purposes: strictly speaking it should allow answers to casual subquestions which are not partial answers. See Section 3.3.
} 


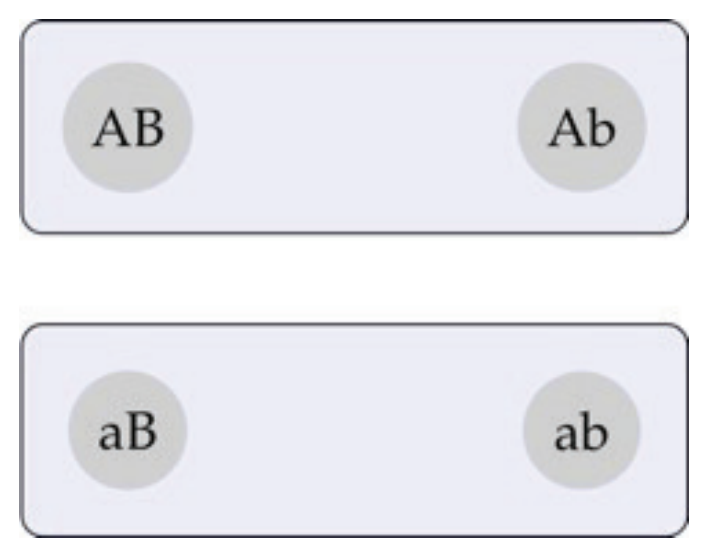

Figure 2. Did A come to the party?

Although this partition contains relatively few cells, it is easy to see that there are various coarse-grained ways to partition up the space. For example, we could ask did A come? giving us the set $\{A$ came; $A$ didn't come $\}$. Or we could ask did anyone come? dividing up logical space into \{someone came; no-one came\}.

We can say that both these new questions are subquestions of the old question who came to the party? in the sense that they are part of the old question. Let's introduce the strict subquestion relation to pick out the parthood relation that involves only coarsening the partition. We can give a precise definition of this relation in terms of entailment relations between the answers to the question and its subquestions:

STRICT: $Q_{1}$ is a strict subquestion of $Q_{2}$ iff a complete answer to $Q_{1}$ entails a partial answer to Q2.32

The notion of parthood picked out by STRICT is useful, but does not cover all the interesting cases. The question if there was beer at the party, did A come? is not a strict subquestion of who came to the party?. Neither there was beer at the party, nor there was not beer at the party allow us to rule out any of the cells in the initial question. However, if we want to use the notion of a subquestion to pick out the kinds of questions we can use to build a resolving answer, this kind of question certainly seems to be of interest. One way to include questions like if there was beer at the party, did A come? within the subquestion relation is to relax the notion of entailment in our definition to allow entailment of answers against

32. The strict subquestion relation is equivalent to Groenendijk and Stokhof's (1984) notion of question-entailment, where $Q_{1}$ entails $Q_{2}$ iff every proposition that completely answers $Q_{1}$ completely answers Q2. A question $Q_{2}$ is a strict subquestion of $Q_{1}$ just in case $Q_{1}$ entails $Q_{2}$ (Roberts 2012: 6.7). 


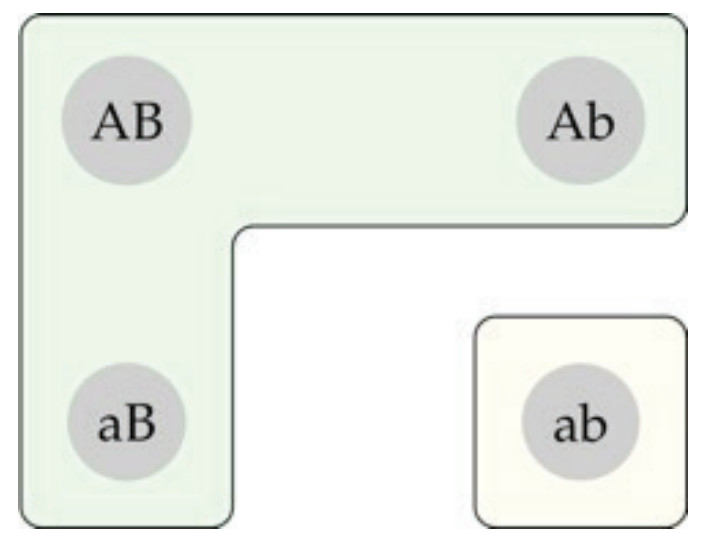

Figure 3. Did anyone come to the party?

a background of accessible information. We can call this kind of subquestion a casual subquestion:

CASUAL: $\mathrm{Q}_{1}$ is a casual subquestion of $\mathrm{Q}_{2}$ iff a complete answer to $\mathrm{Q}_{1}$, together with accessible information, entails a partial answer to $Q_{2}$.

If there was beer at the party, did A come? is a casual subquestion of who came to the party? because an answer to the former question, together with the accessible information that there was beer at the party provides a partial answer to the question of who came to the party.

This move closely parallels Robert's (2004: 210; 2012: 6.11-12, 6.19-20) appeal to contextual entailments. However, whereas she appeals to information that is already in the context, I am appealing to accessible information: information which agents either have, or could obtain given their epistemic situation and capacities. Exactly what counts as accessible is a complex matter, and the fact that information is accessible does not mean that it is easy to get hold of.

Strict subquestions are always simpler than the original question, but casual subquestions can be more complex. In the right context, what food was served at the party? might be a subquestion of who came to the party?, but if the culinary possibilities in a context are richer than the potential guests, the subquestion will have more complete answers than the original question. Although questions with only two answers - such as whether questions and polar questions - have no strict subquestions, they can have casual subquestions. Was there beer at the party? and what food was served at the party? might both be casual subquestions of whether A came to the party? 
Below 'subquestion' will refer to both the strict and the casual notions, and we will need both notions to explain the division of epistemic labour.

\subsection{Building a Resolving Answer from Partial Answers}

Finally, the partition-based understanding of questions gives us a neat way of thinking about how various non-resolving answers can add up to a resolving answer. I will focus on four ways to combine non-resolving answers to reach resolving answers:

i) Combining mention-some answers to reach a mention-all answer;

ii) Combining partial answers to reach a mention-all answer;

iii) Combining partial answers to reach a mention-some answer;

iv) Combining answers to relevant sub-questions to reach a resolving answer.

The simplest way to build a resolving answer is by combining mention-some answers to provide a mention-all answer, adding up the elements on the list to reach the full list. Consider who came to the party?, on its mention-all reading. Mention-some answers to this question, such as $A$ came, and $B$ came can be conjoined to provide a mention-all answer, ruling out all of the cells except that $A$ and $B$ came. 33

We can add up more complex partial answers to reach the same result. For example, the partial answer if $A$ came, then $B$ came allows us to rule out cells in which A came, but B didn't come (the top right cell in Figure 1 ), and if we combine this with $A$ came, then we end up with $A$ and $B$ came.

A mention-some answer can also be constructed out of partial answers. For example, if we know the proposition if A came, then B came (ruling out the top right cell), and learn there was someone at the party (ruling out the bottom right cell), then we end up with the cells in which B came (the left column), giving us the required minimal positive answer. We can also employ a strategy of elimination, reaching a mention-all answer by conjoining negative minimal answers, if we know what the contextually salient domain is. Although answering a mention-some question involves ruling out some possible complete answers, it need not involve ruling out any true minimal answers. When I give a mention-some answer to the question how to skin a cat?, I rule out possible complete answers that include sets of ways that do not include that particular way to skin a cat, but I need not rule out of consideration other possible ways of skinning a cat.

Finally, we can build a resolving answer to a question from answers to its

33. If the question takes an exhaustive reading, then we will also require the conjunction of negative minimal answers. 
casual subquestions. For example, we can combine answers to the questions if there was beer at the party, did A come? and was there beer at the party? to determine whether A came to the party. This combination of answers to sub-questions will be especially important in the case of polar questions-like whether $p$ ? - which have no strict subquestions.

We've covered quite a bit of material, so let's summarise the key claims of the framework:

i. A question is a set of potential exhaustive answers, or a partition of a portion of logical space;

ii. A complete answer to a question is a proposition which rules out all of the cells in the partition corresponding to the question except one;

iii. A partial answer to a question is a proposition that rules out some of the cells in the partition corresponding to the question;

iv. A resolving answer to a question is a proposition which in a conversational context rules out enough cells in the partition corresponding to the question to satisfy the epistemic needs of conversational participants;

v. An agent has knowledge-wh-F, when they know a proposition that is a resolving answer to the embedded question $W h-F$ ?;

vii. An agent has partial knowledge-wh-F, when they know a non-resolving partial answer to the embedded question Wh-F?;

viii. The subquestions of a question are those where a complete answer to those questions entails a non-resolving answer to the initial question, either by themselves (strict subquestions), or with the addition of accessible information (casual subquestions);

vii. Non-resolving partial answers and answers to strict and casual subquestions can add up to a resolving answer to a question.

\section{Subquestions and the Division of Epistemic Labour}

With these tools from the semantics of interrogatives in hand, we can explain how the groups in NASA, PARTY, and LITTER can have collective knowledge in virtue of the knowledge distributed between their members.

Let's start with PARTY, since mention-all readings involve the most straightforward way of partial answers adding up to a resolving answer. We are aiming to explain the truth of the following sentence:

3) The Rowing Club knows who came to the party. 
Assuming that the interrogative who came to the party? takes a mention-all reading, meaning that a resolving answer is a complete list of exactly who came to the party. None of the members of the Rowing Club is in possession of such an answer. Each member of the club only knows a partial list corresponding to a partial answer, meaning that they each have partial knowledge-wh. Crucially, putting these partial lists together yields a complete list of who came. To put this point in terms of partial answers: putting their mention-some answers together would yield a resolving complete answer which ruled out all of the possible combinations of people that might have come, except the set of people that in fact came to the party.

A slight wrinkle emerges when we notice that who came to the party? might take the strongly exhaustive reading associated with complete answers, requiring not just the complete set of people that came, but also the information that no-one else came. Until they put their heads together, none of the members of the Rowing Club knows that any list of party-goers is the complete answer (although they might know that the combined list would be a resolving answer). We might worry that if the interrogative takes an exhaustive reading, the members of the Rowing Club do not have a resolving answer between them. There are two options here. We might take 3) to express a non-exhaustive mention-all reading, meaning that a resolving answer requires only the complete set of positive minimal answers. Alternatively, we could say that the Rowing Club really does collectively know the answer to the question with a strongly exhaustive reading, because although the exhaustivity information is not known by any individual, it would become available after pooling. I think that the first line is more plausible, allowing us to say both that the group knows who came to the party (on the non-exhaustive mention-all reading), and that it stands to gain something by collating its members' knowledge.

In NASA, we are interested in the following sentence:

1) NASA knows how to make a space shuttle

In this case we want to combine individual pieces of knowledge to yield a mention-some answer to the question how to make a space shuttle?. A complete answer to a how-to question will be an exhaustive set of complete methods (i.e. a complete negative and positive assignment of is a way to make a space shuttle to all ways in the domain). This kind of answer is extremely demanding, and for most purposes a resolving answer will be one that provides one complete method for the task at hand. With how to $V$ ? questions, the relevant kind of partial answers will usually be ones that specify a method for a sub-task of the activity of Ving: in this case methods for the various sub-tasks involved in making a space shuttle. A sub-task specifying partial answer provides us with a method for per- 
forming that sub-task. This allows us to rule out the all the possible complete answers to the question which do not contain a complete method involving the relevant method for performing the sub-task. A set of sub-task partial answers can combine to yield a resolving answer to the question, when the methods for performing the various subtasks combine to provide a complete method for performing the overall task. This is exactly the structure which we find in the NASA case. Each of the specialists knows how to perform one sub-task, meaning that they each possess a partial answer to how to make a space shuttle?.34 Putting these partial answers together yields a complete method for building a space shuttle, meaning that the individual-level partial knowledge combines to give grouplevel knowledge-how.

Finally, let's consider LITTER. We need to explain the truth of two sentences:

5) The scouts know whether the whole path is litter-free.

7) The scouts know that the path is litter-free.

Start with 5). Whether-questions are simple $\{p ; n o t-p\}$ partitions, meaning that there are no partial answers to this kind of question. We cannot add partial modifiers to knowledge-whether, meaning that the following sentence is anomalous:

12) \#Arabella knows in part whether Jane came to the party.

To make sense of sentence 5) we will need to build up a resolving answer to the question from the answers to its casual subquestions. In LITTER, each of the scouts searched a portion of the path for litter, meaning that by the end of each of their searches they knew whether there was any litter on their assigned stretch. The question whether stretch $A$ is litter-free? is a casual subquestion of whether the whole path is litter-free? because an answer to the former question, when combined with a body of accessible information -in particular, information about whether all of the other stretches of the path are litter free-will entail an answer to the latter question. So, in this case, all of the scouts know answers to casual subquestions of whether the whole path is litter-free?, which are such that when the answers to these questions are combined together, they entail a complete answer to the question of whether the path is litter free.

34. One might worry that a group could have members who know how to perform relevant subtasks, but do not know how to co-ordinate them. The structure of how-to questions rules out this possibility. Both in the individual case and the collective case, merely knowing how to perform subtasks without knowing how to string them together appropriately is insufficient for knowing a resolving answer to the question how to $V$ ?. When a task is order-sensitive, merely knowing that the task V-ing involves A-ing, B-ing, and C-ing does not suffice for isolating a resolving answer, say the proposition $A$-ing, then B-ing, then $C$-ing is a way to $V$. One of the subquestions to a how-to question will be the question how should we put the other sub-tasks together? 
This leaves us with the collective knowledge-that ascription in 7). A knowledge-that ascription does not semantically express any question, but we can take a parallel approach to this kind of case by considering this proposition against the background of a question supplied by context. A fairly natural move here is to appeal to the question under discussion in the attributor's conversational context (Roberts 2012) and take the that-clause to express an answer relative to that question (see Schaffer 2007; 2008). For example, when we utter sentence 7) thinking about the scenario described in LITTER we are presumably interested in the question whether the path is litter-free? meaning that we are thinking of the proposition that the path is litter-free as an answer to that question. ${ }^{35}$ With this contextually supplied question in place, we can repeat the story about how the answer the path is litter-free was constructed from answers to casual subquestions like whether stretch $A$ is litter-free?. ${ }^{36}$

\section{Fragmented Knowledge}

The Fragmented Knowledge account involves two kinds of conditions: individuallevel conditions concerning the knowledge of group members, and group-level conditions concerning what propositions the group is disposed to act on. So fact, we've motivated the first condition, but we need to see what work the second condition does. Let's start off by considering an account which takes the first kind of condition to be sufficient for collective knowledge in order to motivate the need for the second condition (section 6.1). I will then formulate the second condition and present the full account (section 6.2), before considering some upshots of the account. We will consider the Fragmented Knowledge view's commitment to contextualism about collective knowledge ascriptions (section 6.3), an analogy with the JTB theory of knowledge (section 6.4), how the account fits into the debate between Summativists and non-Summativists (section 6.5), how the account might be adjusted to account for non-propositional accounts of knowledge-wh (section 6.6), and how it handles knowledge-action connections, and group defeat (section 6.7).

35. The appeal to questions under discussion is another place where the contextualist bent of the Fragmented Knowledge account shows up. For non-contextualist theories, background questions are a potential source of error. These errors might either be due to pragmatic (Brown 2006; Pritchard 2010; Rysiew 2007) or psychological effects (Dinges 2018; Gerken 2017; Nagel 2010).

36. The information possessed by group members need not add up to a resolving answer to the question under discussion. If the question under discussion was what interesting objects are on the path? and the scouts have only looked for litter, they could still know there is not litter on the path? relative to what interesting objects are on the path?. 


\subsection{Fragmented Knowledge 1}

If we follow the core intuition that individual-level partial knowledge can add up to group level resolving knowledge, we get the following account of group knowledge:

\section{FRAGMENTED KNOWLEDGE 1}

A group $G$ knows $p$ relative to the question $W h-F$ if:

FK1. Some of the members of $G$ know a set of propositions $\left\{p_{1}, p_{2}, \ldots p n\right\}$, where all of those propositions are either a partial answer to the question Wh-F?, or an answer to a subquestion of Wh-F?;

FK2. Combining the propositions $\left\{p_{1}, p_{2} \ldots p n\right\}$ relative to the question Wh-F? yields $p$ as an answer to the question Wh-F?37.

This account will be able to explain cases of division of labour in the way set out in the last section. ${ }^{8}$ However, the account runs into two problems: it is insufficiently restrictive, and it fails to predict important connections between collective knowledge and action.

FRAGMENTED KNOWLEDGE 1 predicts that individual knowledge is sufficient for group knowledge. If $p$ is a partial answer to the question $W h-F$ ?, and a member of the group knows it, the group will contain members whose knowledge rules out all not- $p$ possibilities, meaning that the group also knows that $p$. If Allie is a member of NASA, and she knows where she left her keys (in the fridge), according to this account, NASA also knows that Allie left her keys in the fridge. 39 This account massively inflates the amount of knowledge had by group agents,

37. This account (and those below) might also be extended to deal with knowledge of subject matters. Knowledge of subject-matters can involve the division of labour: If each member of the history department knows one of the periods of history from 3,000 BCE to 500 CE, then collectively, the history department knows the period 3,00o BCE to 500 CE. These cases can also be modelled in a partition-based framework. Following Lewis (1988a; 1988b) and Yablo (2014; 2016) we might take subject matters to be partitions (with each cell being a way the relevant portion of the world might be) and take knowledge of a subject-matter to relate an agent to a partition (Yablo 2010) which allows us to model collective knowledge of a subject matter in terms of individuals ruling out different cells in that partition. On the relation between subject-matters and questions, see Szabo (2017).

38. One might worry that this account just reinvents the notion of distributed knowledge familiar from epistemic logic (Fagin, Halpern, Moses, \& Vardi 1995; Meyer \& van der Hoek 1995). For a discussion of the relation between distributed knowledge and question-sensitive pooling, see Baltag, Boddy and Smets (2018).

39. This worry is closely related to the 'irrelevant beliefs' criticism of Summativism about group belief (Gilbert 1989; Schmitt 1994). 
and ascribes knowledge which is unhelpful for predicting or explaining group behaviour.

FRAGMENTED KNOWLEDGE 1 also gets into trouble with the following kind of case:

QUARTET: The members of a string quartet are learning to play Mozart's Quartet No. 14 by memory for an upcoming concert. The viola player and cellist have learnt their parts, and the first violinist has learnt both her part and the second violin part in order to understand how their parts fit together. However, the second violinist has not learnt his part. The first and second violin parts are too complicated to play both at the same time by double stopping.

The members of the quartet between them know a set of answers to a set of subquestions of how to play Quartet No. 14?, and these answers add up to a complete way to play the piece, including information about how the parts fit together. This means that according to FRAGMENTED KNOWLEDGE 1, the string Quartet knows how to play Mozart's Quartet No. 14. However, the group does not collectively know how to play Mozart's Quartet No. 14 .

QUARTET nicely brings out the intuition that collective knowledge requires the possibility of collective action. Both in the individual and collective cases, knowledge is the kind of thing that agents are able to act on (a point stressed by Bird 2010: 41-46). There are various ways a group can act on its knowledge, including by using the proposition known as an input to practical reasoning, by asserting the proposition known, or by performing the action which it knows how to do. In cases where the relevant actions involve a division of labour, this connection between knowledge and the possibility of acting on knowledge means that the division of epistemic labour required for group knowledge will mirror the division of practical labour required for successful group action (Harris 2017). In QUARTET, the members of the group have all the knowledge they need, but it is distributed across the players in the wrong way to yield collective knowledge-how because it does not correspond to the natural division of practical labour involved in playing the piece.

\subsection{Fragmented Knowledge 2}

In order to reflect the connection between knowledge and action highlighted by QUARTET, we need to add an extra condition on collective knowledge: that the proposition known be available for collective action. I understand availability in the following way: 
AVAILABILITY: A proposition $p$ is available to collective action for some group $G$ iff $G$ is disposed to act on the basis of $p$ in a relevant set of groupappropriate tasks, where this disposition is indexed to situations which are both environmentally normal, and involve the group functioning in accordance with its constitution. $4^{\circ}$

This condition relativises availability to two context-sensitive indexes: relevant tasks, and situations. The context-sensitivity of group ability ascriptions ought to be unsurprising given the context-sensitivity of ability ascriptions in general (Kratzer 1977). Let's unpack these two dimensions of context-sensitivity in turn.

In general, when we're thinking about whether a group knows that $p$, one thing we should consider is whether the group is disposed to assert $p$, use $p$ as a premise in practical reasoning, and act as if $p$ were true. However, our interest can be focused on a more specific set of tasks, either by the kind of group under consideration, or by contextual factors. For example, what Schmitt calls chartered groups are set up to perform specific kinds of actions (Schmitt 1994: 172-173), and when we are considering these groups, the relevant tasks will plausibly be those specified by the group's constitution. The shuttle-building department in NASA might be set up so that it can only make space shuttles. If this is so, the shuttle-building department can't know where Allie's keys are, because (in normal situations) this proposition is not suitable for employment in the task of building a shuttle.

The set of actions under consideration can also be restricted by contextual salience. In my description of QUARTET I snuck in a salient task - playing the piece live from memory - in order to elicit the intuition that the Quartet did not know how to play the piece. If I had made a different task salient, our intuitions would have differed. If recording the piece was a salient task we might have judged that the group did know how to play the piece, because the group could have exercised their distributed knowledge to record the piece successfully by having the first violinist lay down both the first and second violin parts. ${ }^{41}$

In addition to the tasks variable, AvAILABLITy is also sensitive to salient situations. When evaluating the availability of some proposition, I suggest that we look to situations which are both environmentally normal, and involve the group working in accordance with its constitution. We need to look to normal environments to avoid group knowledge being undermined by a hostile environment. NASA still knows how to make a space shuttle during a government shutdown, it's just that they can't act on that knowledge. We need to look at situations in which the group is working in accordance with its constitution to reflect how a

40. The task-sensitivity in this condition takes inspiration from Hawley (2003).

41. See Birch (2018) for a narrower conception of group knowledge-how that excludes such cases of prepackaged co-operation. 
group's constitution affects its knowledge. For example, a jury might be forbidden by its constitution from employing hearsay evidence in its deliberations, meaning that although all the members of a group might know that the accused is guilty, the group collectively does not know that fact because it is not actionable in accordance with its constitution..$^{42}$ A group's constitution can restrict the kind of evidence it employs (as in the jury case), and it can also restrict the types of proposition a group can know, or require specific procedures for action (see Lackey 2016: 272-273).43

Adding the availability of a proposition to FRAGMENTED KNOWLEDGE 1 won't quite fix things, since a proposition might be available to collective action for some reason which has nothing to do with individual knowledge. We need to add both Availability, and the requirement that a proposition is available to collective action because it is known by members of the group. This gives us the following account:

FRAGMENTED KNOWLEDGE 2

A group $G$ knows that $p$ relative to the question $W h-F$ ? only if:

FK1. Some of the members of $G$ know a set of propositions $\left\{p_{1}, p_{2}, \ldots p n\right\}$, where all of those propositions are either a partial answer to the question $W h-F$ ?, or an answer to a subquestion of Wh-F?.

FK2. Combining the propositions $\left\{p_{1}, p_{2}, \ldots p n\right\}$ relative to $W h-F$ ? yields $p$ as an answer to Wh-F?.

$F_{3}$. The proposition $p$ is available to $G$ for collective action;

FK4. Condition FK3 obtains because of conditions FK1 and FK2.

In the remainder of this section, I will unpack some features of the account, and deal with some worries.

\subsection{Contextualism}

At a number of points above I have noted ways in which knowledge-wh ascriptions are context-sensitive. These mechanisms of context-sensitivity are a little

42. This case is adapted from Schmitt (1994).

43. A special case is the requirement for consensus. If a group's constitution requires that its members agree on a question before it can act, then the possibility of consensus is a requirement for collective knowledge. If the group's constitution makes no such requirement, then it is possible for the group to know although they are not in a position to reach consensus. 
complex, so it is worth unpacking how they affect the Fragmented Knowledge account. Strictly speaking, FRAGMENTED KNOWLEDGE 2 is an account of the knowledge-wh relation. To formulate an account of the semantics of collective knowledge ascriptions, we can employ semantic ascent, making clear the contextual variables. Starting with collective knowledge-wh ascriptions, we get:

SEMANTICS FOR FRAGMENTED KNOWLEDGE 2

A sentence of the form ' $G$ knows Wh- $F$ ' is true in a context $C$ iff:

SFK1. Some of the members of $G$ know a set of propositions $\left\{p_{1}, p_{2}\right.$, ...pn\}, where all of those propositions are either a partial answer to the question Wh-F? - which is the question expressed by 'Wh-F?' in $C$ - or an answer to a subquestion of Wh-F?;

SFK2. Combining the propositions $\{p 1, p 2 \ldots p n\}$ relative to $W h-F$ ? yields $p$ as an answer to $W h-F$ ?, and given the discussants' epistemic needs and purposes in $C, p$ counts as a resolving answer to Wh-F?;

$\mathrm{SFK}_{3}$. Given the situations and tasks that are salient in $C$, the proposition $p$ counts as available to $G$ for collective action;

$\mathrm{SFK}_{4}$. Condition $\mathrm{SK}_{3}$ obtains because of conditions SFK1 and SFK2.

For a collective knowledge-that ascription, we replace $\mathrm{SFK}_{1}$ with $\mathrm{SFK}_{1}{ }^{*}$, and include $\mathrm{SFK}_{2}, \mathrm{SFK}_{3}$, and $\mathrm{SFK}_{4}$ as above:

$\mathrm{SFK}_{1}{ }^{*}$. Some of the members of $G$ know a set of propositions $\left\{p_{1}, p_{2}\right.$, ...pn\}, where all of those propositions are either a partial answer to the question Wh-F? - which is the salient question in $C$ - or an answer to a subquestion of Wh-F?.

This semantics relies on a number of bits of contextualist machinery. First, the semantics for knowledge-that ascriptions in $\mathrm{SFK}_{1}^{*}$ ) appeals to a salient question to provide a background for the ascription. Secondly, the meaning of the interrogative will be sensitive to a number of features of context (see Footnote 31). Thirdly, the availability relation in condition $\mathrm{SFK}_{3}$ of the account is sensitive to salient tasks and situation, which can be a function of context, and the kind of group in question. These commitments mean that the account will be vulnerable to criticisms of contextualism, but I hope to have made the case along the way that contextualism is necessary to make sense of the shiftiness of both knowledge-wh and collective ability ascriptions. 


\subsection{Analogy to Justified True Belief Theory of Knowledge}

The conditions in FRAGMENTED KNOWLEDGE 2 play rather similar roles to justification and belief in the Justified True Belief account of individual knowledge, which suggests that the individual conditions might be used to develop accounts of collective justification, and collective belief.

We can think of the individual knowledge that goes into the base of collective knowledge in conditions FK1 and FK2 in FRAGMENTED KNOWLEDGE 2 as the group's epistemic potential (see Baltag, Boddy, \& Smets 2018), or its propositional justification. We can think of $\mathrm{FK}_{3}$ as a belief condition, given the close connections between believing some proposition and acting as if it were true. FK 4 functions much like a basing relation in the individual case.

This analogy suggests that we might extract the conditions in FRAGMENTED KNOWLEDGE 2 to give accounts of group belief, group justification, and also of collective ignorance.

Extant accounts of collective belief either work in a judgement aggregation framework (List \& Pettit 2011) or appeal to joint commitment (Gilbert 1987; 1989). Following the lead of dispositionalists about belief in the individual case (Ryle 1949; Marcus 1990; Schwitzgebel 2002), we might ask whether we might analyse collective belief in terms of dispositions to collective action. As it stands, AVAILABILITY gives us a decent first pass at a dispositionalist account of group belief:

\section{BELIEF}

A group $G$ believes $p$, only if:

FB1. The proposition $p$ is available to $G$ for collective action.

$\mathrm{FK}_{1}$ and $\mathrm{FK}_{2}$ can be thought of as providing the kind of justification required for collective knowledge. Knowledge requires truth, and a rather stringent level of justification, so to get a general account of justified belief, we need to switch the individual-level ingredients from individual knowledge of true propositions to individual justified belief in any (true or false) proposition. This gives us the following account of collective (propositional) justification:

FRAGMENTED JUSTIFICATION

A group $G$ is justified to believe that $p$ relative to the question $W h-F$ ? only if:

FJ1. Some of the members of $G$ have justified beliefs in a set of propositions $\left\{p_{1}, p_{2}, \ldots p n\right\}$, where all of those propositions are either a partial answer to the question Wh-F?, or an answer to a subquestion of Wh-F? 
FJ2. Combining the propositions $\left\{p_{1}, p_{2} \ldots p n\right\}$ relative to the question Wh-F? yields $p$ as an answer to the question Wh-F?

Combining FRAGMENTED JUSTIFICATION with Belief and the basing claim in $\mathrm{FK}_{4}$ would give us an account of group doxastic justification.

This account of collective justification helps us to understand the epistemic situation of groups that are not capable of collective action. This helps us to respond to a potential worry. It is natural to ascribe knowledge to widely dispersed social groups that do not have the institutional structures required for collective action. For example, we might say that the victims of austerity know the human cost of austerity politics, although this group cannot perform social actions in the same way that a corporation or political party might. 44 Taking this account of collective justification we can say that this group has collective propositional justification for a host of claims about the human cost of austerity politics, although the group does not collectively know these claims because it is not disposed to act on their basis. This group is in a position to know the human cost of austerity politics, but doesn't strictly speaking have knowledge (Lackey 2014: 294-295).

Assuming that ignorance is the absence of knowledge (Le Morvan \& Peels 2016), we can also use FRAGMENTED KNOWLEDGE 2 to give us an account of collective ignorance. The four conditions in the account of collective knowledge suggests that there are four basic ways for a group to be ignorant that $p$ relative to some question Wh-F?:

i) If the members of the group do not know answers to subquestions of WhF;

ii) If combining partial answers to Wh-F? known by members of the group does not yield $p$;

iii) If $p$ is not available to collective action;

iv) If $p$ is available to collective action, but not because of relevant knowledge had by group members.

Although we haven't had space to defend these accounts of collective justification, belief and ignorance, the existence of these accounts is evidence that thinking about group epistemology in a question-based framework is productive.

\subsection{Summativism and Non-Summativism}

FRAGMENTED KNOWLEDGE 2 is a non-Summative account of group knowledge, because it denies SUMnNow. This account allows that the object of collective

44. Assuming that anti-austerity campaigns advocate for, and don't act on behalf of the victims of austerity. 
knowledge might be distributed between the members of a group, meaning that no individual knows what the group does. Although it is non-Summativist, this account is still reductivist: collective knowledge reduces to individual-level partial knowledge (FK1, $\left.\mathrm{FK}_{2}\right)$, dispositions regarding collective action $\left(\mathrm{FK}_{3}\right)$, and the relation between them $\left(\mathrm{Fk}_{4}\right)$. According to this account, to tell a story about a group's knowledge, all we need is a story about its members' knowledge and the role of this knowledge in the life of the group.

Unlike Bird's (2010: 33-35) account, which allows that group knowledge can float completely free of individual knowledge, FRAGMENTED KNOWLEDGE 2 claims that collective knowledge relies on individual knowledge. If the members of a group that have relevant partial knowledge were to lose it (or were to leave the group) the group would thereby lose its knowledge. ${ }^{45} \mathrm{In}$ terestingly, because of the availability condition, this account also predicts that a group might also lose or gain knowledge by changing whose knowledge it acts on. If a group were to suddenly include its female members on decision-making committees, its collective knowledge would thereby increase because the group would be disposed to act on more of its members' knowledge.

\subsection{Non-Propositional Approaches to Knowledge-wh}

I have taken on the assumption that knowledge-wh and -how are propositional to simplify the presentation, which also helpfully makes clear the generality of the Fragmented Knowledge account. However, it would be possible to reformulate a version of this account that allows for non-propositional knowledge. The idea at the centre of this account is that group knowledge of some object can involve individuals knowing different parts of that object. We have focused on a way to elaborate this idea using questions and sub-questions, but there are different possible pictures corresponding to different pictures of the part-whole structure of the objects of knowledge.

As a proof of concept consider someone who thought that knowledge how to do something was identical with the ability to do it. Someone who was committed to this kind of theory might claim that a group knows how to do some activity when the members of the group are able to perform a suitable set of sub-activities and the group is able to co-ordinate those activities in collective

45. The literature on uninvention provides a diverse set of examples of this phenomenon. On the uninvention of nuclear weapons see Mackenzie and Spinardi (1995), and on the uninvention of mathematical proofs see Steingart (2012). Both of these examples involve the loss of knowledge due to the death of relevant individuals. For an example involving uninvention due to deliberate exclusion, see Hicks's (2017) account of the role of women in early electronic computing in the UK. 
action (see Birch 2018 on co-ordination enablement). Instead of fragmenting the answers to a question, this theory would fragment an activity into sub-activities. It isn't just questions that can be fragmented: pretty much any possible object of knowledge-wh and how can be. ${ }^{6}$

That said, it's worth stressing that the assumption that knowledge-wh is a relation to a proposition need not lead to a commitment to a strong form of intellectualism (Stanley \& Williamson 2001). One can think that the object of knowledge-wh and -how is a proposition or question, whilst thinking that this relation is radically different to the one involved in knowledge-that (Glick 2011). For example, one might think that knowledge-how involves an ability-type relation to a question (Habgood-Coote 2019), and still employ the machinery of questions and subquestions in the way I have done above.

\subsection{Knowledge Norms and Group Defeat}

Lackey (2014) argues that the existence of social knowledge-that is, group knowledge that is not accompanied by individual knowledge of the proposition in question-is incompatible with the epistemic norms governing action, and the possibility of psychological defeaters for social knowledge. The Fragmented Knowledge account is well-placed to respond to these concerns. Let's take them in turn.

Lackey's first worry appeals to the sufficiency direction of the knowledge norm of action:

KA: If one knows that $p$, then it is epistemically permissible to act as if $p$.

Lackey (2014: 285-291) points out that in some cases in which Bird (2010) countenances collective knowledge, none of the members of the group would be epistemically well-positioned to act as if $p$. Since a group can only act through its members, KA together with the absence of appropriate individual action suggests that the groups in these cases do not possess knowledge. 47

The Fragmented Knowledge account closes the gap between collective knowledge and epistemically permissible action. The availability condition $\left(\mathrm{FK}_{3}\right)$ bakes a knowledge-action connection into FRAGMENTED KNOWLEDGE 2, so

46. One caveat: some views about the object of knowledge-how - such as objectualism (Bengson \& Moffett 2011a) - aren't well placed to explain partial knowledge-wh ascriptions (see Pavese 2017), meaning they will struggle to explain the cumulative reading of group knowledge ascriptions.

47. Lackey's objection targets both cases of the division of epistemic labour and Bird's (2010: 30-36) publication cases. This response can be used to defend the presence of collective knowledge in both cases, but FRAGMENTED KNOWLEDGE 2 does not predict that the scientific community knows in the publication cases (see Section 6.5). 
the question is whether the presence of distributed knowledge renders these actions epistemically appropriate. It isn't hard to think of cases in which a group knows, but a member's action is nonetheless inappropriate. If one member of the Rowing Club were to correctly guess who came to the party, and then made a statement on behalf of the group, this assertion would be epistemically improper. However, I submit that what goes wrong in this case is not that the group does not know, but that the member's assertion fails to express the collective's knowledge. We can find parallel cases in the individual case: if you ask me whether I'm free for dinner and I guess and say yes, my assertion is inappropriate, even if I do in fact know that I'm available. In both cases what goes wrong is that the assertions do not express the agents' knowledge. Turri (2011) proposes to tweak the norm of assertion to one requiring that an assertion expresses knowledge, and we can make a similar tweak to the sufficiency direction of the knowledge norm of action. This gives us the following norm:

$\mathrm{KA}^{*}$ : if one's action expresses knowledge that $p$, then it is epistemically permissible to act as if $p$.

Putting KA* together with FRAGMENTED KNOWLEDGE 2, a group's actions are epistemically appropriate when the members acting on behalf of the group are accessing the knowledge distributed amongst the members of the group. It is difficult to find counterexamples to this picture: this would require finding a case in which a group member's action on behalf of the group accesses the distributed knowledge of the group, but that action is not epistemically appropriate.

Lackey's second worry centres around the possibility of group knowledge being defeated (see also Carter 2015). We would expect that like individual knowledge, group knowledge can be defeated by various psychological and normative facts. Lackey points out that Bird's (2010) account predicts that a group can know that $p$ whilst every member of that group believes not- $p$. Since most accounts of collective belief predict that the group in this case would collectively believe that not- $p,{ }^{8}$ this suggests that Bird's account is incompatible with psychological defeat for group knowledge.

The Fragmented Knowledge account faces a related worry. Because this account only looks to members' knowledge and collective dispositions to determine the presence of collective knowledge, it allows distributed knowledge that radically diverges from individual beliefs. For example, the members of NASA might each know how to do their task whilst having a false belief about the number of tasks involved in making a space shuttle, and the members of the Rowing

48. I will set to one side the question of whether the group has collective belief in these cases. If group belief is merely a matter of group-level dispositions (see Section 6.4.) FRAGMENTED KNOWLEDGE 2 can save the connection between group knowledge and group belief. 
club might know partial lists of who came while all having false beliefs about how many people came. In both cases, the group might know some proposition composed of partial answers, although all members of the group believe that that proposition is false. 49

Although FRAGMENTED KNOWLEDGE 2 allows for collective knowledge in the face of individual disbelief, it leaves space for a couple of mechanisms of defeat.

One way collective knowledge can be defeated is via defeat of individuallevel partial knowledge. If the Rowing club's putative collective knowledge depends on Ann knowing that A and B came to the party, but all other members of the club falsely believe that A didn't come to the party, then-even if Ann is not aware of her fellows' beliefs - her belief may be subject to normative defeat on the grounds that she should have known about her co-members countervailing beliefs. This mechanism doesn't require universal false belief: even a moderate level of disagreement at the individual level might knock out the individual knowledge required for collective knowledge. Note that whether individual knowledge is defeated depends on the false proposition believed: the false belief that only four people came to the party will not defeat knowledge that A came.

Another mechanism for defeat exploits availabiLITy. Even if individual-level partial knowledge remains undefeated, individual false beliefs about the answer to a question may modify the group's dispositional states. If all the members of the Rowing Club falsely believe that exactly four people came to the party, they may block the group from publishing a report that claims (correctly) that only three people came. If individuals stop the group from acting on distributed knowledge, then according to FRAGMENTED KNOWLEDGE 2, the group will no longer know who came to the party because it will not have appropriate dispositions.

\section{Conclusion}

Philosophical discussions about group knowledge have proceeded on the assumption that if there is an interesting relation between individual and group knowledge, it must be at the level of individual propositions. In this paper I have tried to shake this assumption, considering cases of the division of epistemic labour in which a group knows some body of information when the members of the group know various different parts of that body of information. I have argued that cases of the division of labour can be understood by appealing to the mereological structure of questions and have proposed the Fragmented Knowl-

49. This may be particularly common with collective knowledge-how: in the individual case there are many cases in which knowledge-how is accompanied by false belief. See Wallis (2008: 139-140), Cath (2011), Glick (2011: 409), Brownstein and Michaelson (2016). 
edge account to explain the kind of knowledge present in these cases. Although I have stopped short of proposing that FRAGMENTED KNOWLEDGE 2 is the only way to think about collective knowledge, I think that it explains a swathe of central cases, and sheds light on some important features of group knowledge, and collective mentality more generally.

To close, I want to note some ways in which the framework developed in this paper can be extended. First, the approach of using questions and subquestions to think about the epistemic state of a group could be extended to develop accounts of collective justification, belief, and ignorance as we saw in Section 6.4. Generalising further, we might use a question-focused account to make sense of group inquiry and the collective production of knowledge. Secondly, the Fragmented knowledge account might be used to help us to think about epistemic principles of group design. If group knowledge is a matter of individual knowledge being available to collective action, then maximising collective knowledge involves combining mechanisms that access individual knowledge with those that facilitate collective action. Thirdly, although we've focused on relatively small and well-structured groups, the account might be scaled up to think about larger groups. This might be useful as part of a project of demystifying political and scientific knowledge by revealing them as involving massively distributed knowledge.

\section{Acknowledgements}

Thanks to two reviewers and an editor at this journal, Alexander Bird, Jessica Brown, Josh Dever, Jeroen de Ridder, Miguel Egler, Keith Harris, Katherine Hawley, Megan Hyska, Bruno Jacinto, Matthew McGrath, Richard Pettigrew, Brian Weatherson, Fenner Tanswell, Caroline Touborg and an audience in St Andrews. Special thanks to James Andow for help with the statistical tests in Footnote 9, and to Jessica Brown for suggesting QUARTET.

\section{References}

Aloni, Maria (2008). Concealed Questions under Cover. Grazer Philosophische Studien, 77(1), 191-216. https://doi.org/10.1163/18756735-90000848

Baltag Alexandru, Rachel Boddy, and Sonja Smets (2018). Group Knowledge in Interrogative Epistemology. In Hans van Ditmarsch and Gabriel Sandu (Eds.), Jaakko Hintikka on Knowledge and Game Theoretical Semantics (131-164). Springer. https://doi. org/10.1007/978-3-319-62864-6_5

Beck, Sigrid and Yael Sharvitt (2002). Pluralities of Questions. Journal of Semantics, 19(2), 105-157. https://doi.org/10.1093/jos/19.2.105 
Bengson, John and Marc Moffett (2011a). Non-Propositional Intellectualism. In John Bengson and Marc Moffett (Eds.), Knowing How: Essays on Knowledge, Mind, and Action (161-195). Oxford University Press. https://doi.org/10.1093/acprof:o so/9780195389364.003.0007

Bengson, John and Marc Moffett (2011b). Two Conceptions of Mind and Action: Knowledge How and the Philosophical Theory of Intelligence. In John Bengson and Marc Moffett (Eds.), Knowing How: Essays on Knowledge, Mind, and Action (3-55). Oxford University Press. https://doi.org/10.1093/acprof:oso/9780195389364.003.0001

Berman, Stephen (1991). On the Semantics and Logical Form of Wh-Clauses (Doctoral dissertation). University of Massachusetts at Amherst.

Bhatt, Rajesh (2008). Covert Modality in Non-Finite Contexts. De Gruyter Mouton.

Birch, Jonathan (2018). Joint Know-How. Philosophical Studies. Advance online publication. https://doi.org/10.1007/s11098-018-1176-6

Bird Alexander (2010). Social Knowing: The Social Sense of 'Scientific Knowledge'. Philosophical Perspectives, 24(1), 23-56. https://doi.org/10.1111/j.1520-8583.2010.00184.x

Bird, Alexander (2014). When is There a Group That Knows? Scientific Knowledge as Social Knowledge. In Jennifer Lackey (Ed.), Essays in Collective Epistemology (42-63). Oxford University Press. https://doi.org/10.1093/acprof:oso/9780199665792.003.0003

Boddy, Rachel (2014). Epistemic Issues and Group Knowledge (MSc thesis). University of Amsterdam. Retrieved from http://www.illc.uva.nl/Research/Publications/Reports/ MoL-2014-03.text.pdf

Boër, Steven and William Lycan (1986). Knowing Who. MIT Press.

Braun, David (2006). Now You Know Who Hong Oak Yun Is. Philosophical Issues, 16(1), 24-42. https://doi.org/10.1111/j.1533-6077.2006.00101.x

Brown, Jessica (2006). Contextualism and Warranted Assertibility Manoeuvres. Philosophical Studies, 130(3), 407-435. https://doi.org/10.1007/s11098-004-5747-3

Brownstein, Michael and Eliot Michaelson (2016). Doing without Believing: Intellectualism, Knowledge-How, and Belief-Attribution. Synthese, 193(9), 2815-2836. https:// doi.org/10.1007/s11229-015-0888-9

Carter, J. Adam (2015). Group Knowledge and Epistemic Defeat. Ergo: An Open Access Journal of Philosophy, 2(28), 711-735. https://doi.org/10.3998/ergo.12405314.0002.028

Cath, Yuri (2011). Knowing How Without Knowing That. In John Bengson and Marc Moffett (Eds.), Knowing How: Essays on Knowledge, Mind, and Action (113-35). Oxford University Press. https://doi.org/10.1093/acprof:oso/9780195389364.003.0005

Cath, Yuri (2019). Knowing How. Analysis, 79(3), 487-503. https://doi.org/10.1093/analys/ anz027

Ciardelli, Ivano, Jeroen Groenendijk, and Floris Roelofsen (2015). On the Semantics and Logic of Declaratives and Interrogatives. Synthese, 192(6), 1689-1728. https://doi. org/10.1007/s11229-013-0352-7

Ciardelli, Ivano, Jeroen Groenendijk, \& Floris Roelofsen (2018). Inquisitive Semantics. Oxford University Press. https://doi.org/10.1093/oso/9780198814788.001.0001

Collins, Patricia Hill (2000) Black Feminist Thought: Knowledge Consciousness and the Politics of Empowerment. Routledge.

Cotnoir, Aaron J. (2013). Composition as General Identity. In Karen Bennett and Dean W. Zimmerman (Eds.), Oxford Studies in Metaphysics (Vol. 8, 294-322). Oxford University Press. https://doi.org/10.1093/acprof:oso/9780199682904.003.0007 
Craig, Edward (1990). Knowledge and the State of Nature: An Essay in Conceptual Synthesis. Oxford University Press.

de Ridder, Jeroen (2014). Epistemic Dependence and Collective Scientific Knowledge. Synthese, 191(1), 1-17. https://doi.org/10.1007/s11229-013-0283-3

de Ridder, Jeroen (2019). How Many Scientists Does It Take to Have Knowledge? In Kevin McCain and Kostas Kampourakis (Eds.), What is Scientific Knowledge? An Introduction to Contemporary Epistemology of Science (3-17). Routledge. https://doi. org/10.4324/9780203703809-1

DeRose, Keith (2009). The Case for Contextualism: Knowledge, Skepticism, and Context (Vol. 1). Oxford University Press.

Dever, Joshua (1991). Variables (Doctoral dissertation). University of California Berkeley. Retrieved from http://exordio.qfb.umich.mx/archivos\%2opdf\%2ode\%2otrabajo\%2O umsnh/aphilosofia/Variables.pdf

Devitt, Michael (2011). Methodology and the Nature of Knowing How. Journal of Philosophy, 108(4), 205-218. https://doi.org/10.5840/jphil2011108412

Dinges, Alexander (2018). Anti-Intellectualism, Egocentrism and Bank Case Intuitions. Philosophical Studies, 175(11), 2841-2857. https://doi.org/10.1007/s11098-017-0984-4

Fagan, Melinda Bonnie (2011). Is There Collective Scientific Knowledge? Arguments from Explanation. Philosophical Quarterly, 61(243), 247-269. https://doi.org/10.1111/ j.1467-9213.2010.676.x

Fagan, Melinda (2012). Collective Scientific Knowledge. Philosophy Compass, 7(12), 821831. https://doi.org/10.1111/j.1747-9991.2012.00528.x

https://doi.org/10.1093/acprof:oso/9780199936502.003.0008

Fagin, Ronald, Joseph Y. Halpern, Yoram Moses, and Moshe Vardi (1995). Reasoning About Knowledge. MIT Press.

Fantl, Jeremy (2008). Knowing-How and Knowing-That. Philosophy Compass, 3(3), 451470. https://doi.org/10.1111/j.1747-9991.2008.00137.x

Fantl, Jeremy and Matthew McGrath (2009). Knowledge in an Uncertain World. Oxford University Press. https://doi.org/10.1093/acprof:oso/9780199550623.001.0001

Fricker, Miranda (2007). Epistemic Injustice: Power and the Ethics of Knowing. Oxford University Press. https://doi.org/10.1093/acprof:oso/9780198237907.001.0001

Gerken, Mikkel (2017). On Folk Epistemology: How We Think and Talk about Knowledge. Oxford University Press. https://doi.org/10.1093/oso/9780198803454.003.0002

Gilbert, Margaret (1987). Modelling Collective Belief. Synthese, 73(1), 185-204. https:// doi.org/10.1007/BF00485446

Gilbert, Margaret (1989). On Social Facts. Routledge.

Gilbert, Margaret (2004). Collective Epistemology. Episteme, 1(2), 95-107. https://doi. org/10.3366/epi.2004.1.2.95

Gillon, Brendan (1992). Towards a Common Semantics for English Count and Mass Nouns. Linguistics and Philosophy, 15(6), 597-639. https://doi.org/10.1007/BF00628112

Glick, Ephraim (2011). Two Methodologies for Evaluating Intellectualism. Philosophy and Phenomenological Research, 83(2), 398-434. https://doi.org/10.1111/j.19331592.2010.00438.x

Goldberg, Sandy (2011). The Division of Epistemic Labor. Episteme, 8(1), 112-125. https:// doi.org/10.3366/epi.2011.0010

Goldman, Alvin I. (2004). Group Knowledge versus Group Rationality: Two Approaches to Social Epistemology. Episteme, I(1), 11-22. https://doi.org/10.3366/epi.2004.1.1.11 
Groenendijk, Jeroen and Martin Stokhof (1982). Semantic Analysis of WH-Complements. Linguistics and Philosophy, 5(2), 175-233. https://doi.org/10.1007/BF00351052

Groenendijk, Jeroen and Martin Stokhof (1984). Studies on the Semantics of Questions and the Pragmatics of Answers (Doctoral dissertation). Institute for Logic, Language \& Computation (ILLC), University of Amsterdam. Retrieved from http://dare.uva.nl/ record/123669

Groenendijk, Jeroen and Martin Stokhof (1993). Interrogatives and Adverbs of Quantification. In K. Bimbo and A. Mate (Eds.), Proceedings of the $4^{\text {th }}$ Symposium on Logic and Language (1-19). Aron Publishers.

Habgood-Coote, Joshua (2018a). Knowledge-How Is the Norm of Intention. Philosophical Studies, 175(7), 1703-1727. https://doi.org/10.1007/s11098-017-0931-4

Habgood-Coote, Joshua (2018b). The Generality Problem for Intellectualism. Mind and Language, 33(3), 242-262. https://doi.org/10.1111/mila.12177

Habgood-Coote, Joshua (2019). Knowledge-How, Abilities, and Questions. Australasian Journal of Philosophy, 97(1), 86-104. https://doi.org/10.1080/00048402.2018.1434550

Hamblin, Charles L. (1958). Questions. Australasian Journal of Philosophy, 36(3), 159-168. https://doi.org/10.1080/00048405885200211

Hardwig, John (1985). Epistemic Dependence. Journal of Philosophy, 82(7), 335-349. https://doi.org/10.2307/2026523

Harris, Keith (2017). Group Knowledge and Epistemically Rational Action. Unpublished manuscript.

Hawley, Katherine (2003). Success and Knowledge-How. American Philosophical Quarterly, 40(1), 19-31.

Hawthorne, John and Jason Stanley (2008). Knowledge and Action. Journal of Philosophy, 105(10), 571-590. https://doi.org/10.5840/jphil20081051022

Hayek, Friedrich August (1945). The Use of Knowledge in Society. The American Economic Review, 35(4), 519-530.

Higginbotham, James (1996). The Semantics of Questions. In Shalom Lappin (Ed.), Handbook of Contemporary Semantic Theory. Blackwell.

Huebner, Bryce, Kukla, Rebecca, and Winsberg, Eric (2017). Making an Author in Radically Collaborative Research in Scientific Collaboration and Collective Knowledge: New Essays, Thomas Boyer-Kassem, Conor Mayo-Wilson, and Michael Weisberg (eds) New York: Oxford University Press pp. 95-116.

Hutchins, Edwin (1995). Cognition in the Wild. MIT Press.

Jenkins, Anna, David Dodell-Feder, Rebecca Saxe, and Joshua Knobe (2014). The Neural Bases of Directed and Spontaneous Mental State Attributions to Group Agents. PLoS ONE, 9(8), e105341. https://doi.org/10.1371/journal.pone.0105341

Karttunen, Lauri (1977). Syntax and Semantics of Questions. Linguistics and Philosophy, 1, 3-44. https://doi.org/10.1007/BF00351935

Kitcher, Philip (1990). The Division of Cognitive Labor. Journal of Philosophy, 87(1), 5-22. https://doi.org/10.2307/2026796

Kitcher, Philip (1991). Socializing Knowledge. Journal of Philosophy, 88(11), 675-676. https://doi.org/10.5840/jphil1991881115

Klausen, Søren (2015). Group Knowledge: A Real-World Approach. Synthese, 192(3), 813-839. https://doi.org/10.1007/s11229-014-0589-9

Knorr Cetina, Karin (1999). Epistemic Cultures: How the Sciences Make Knowledge. Harvard University Press. 
Kratzer, Angelika (1977). What 'Must' and 'Can' Must and Can Mean. Linguistics and Philosophy, I(3), 337-355. https://doi.org/10.1007/BF00353453

Kukla, Rebecca (2012). "Author TBD": Radical Collaboration in Contemporary Biomedical Research. Philosophy of Science, 79(5), 845-858. https://doi.org/10.1086/668042

Lackey, Jennifer (2012). Group Knowledge Attributions. In Jessica Brown, and Mikkel Gerken, (Eds.), Knowledge Ascriptions (243-267). Oxford University Press. https://doi. org/10.1093/acprof:oso/9780199693702.003.0011

Lackey, Jennifer (2014). Socially Extended Knowledge. Philosophical Issues, 24(1), 282298. https://doi.org/10.1111/phis.12034

Lackey, Jennifer (2016). What Is Justified Group Belief? Philosophical Review, 125(3), 341396. https://doi.org/10.1215/00318108-3516946

Lahiri, Utpal (2002). Questions and Answers in Embedded Contexts. Oxford University Press.

Landman, Fred (1989). Groups I. Linguistics and Philosophy, 12(5), 559-605. https://doi. org/10.1007/BF00627774

Le Morvan, Pierre, and Rik Peels (2016). The Nature of Ignorance: Two Views. In Rik Peels and Martijn Blaauw (Eds.), The Epistemic Dimensions of Ignorance (12-32). Cambridge University Press. https://doi.org/10.1017/9780511820076.002

Lewis, David (1988a). Relevant Implication. Theoria, 54(3), 161-174. https://doi. org/10.1111/j.1755-2567.1988.tb00716.x

Lewis, David (1988b). Statements Partly about Observation. Philosophical Papers, 17(1), 1-31. https://doi.org/10.1080/05568648809506282

Linnebo, Øystein and David Nicolas (2008). Superplurals in English. Analysis, 68(299), 186-197. https://doi.org/10.1111/j.1467-8284.2008.00737.x

List, Christian (2005). Group Knowledge and Group Rationality: A Judgment Aggregation Perspective. Episteme, 2(1), 25-38. https://doi.org/10.3366/epi.2005.2.1.25

List, Christian and Phillip Pettit (2011). Group Agency: The Possibility, Design, and Status of Corporate Agents. Oxford University Press.

Ludwig, Kirk (2016). From Individual to Plural Agency: Collective Action I. Oxford University Press. https://doi.org/10.1093/acprof:oso/9780198755623.001.0001

MacKenzie Donald and Graham Spinardi (1995). Tacit Knowledge, Weapons Design, and the Uninvention of Nuclear Weapons. American Journal of Sociology, 101(1), https:// doi.org/10.1086/230699

Marcus, Ruth Barcan (1990). Some Revisionary Proposals about Belief and Believing. Philosophy and Phenomenological Research, 50(suppl.), 133-153. https://doi. org/10.2307/2108036

Masto, Meghan (2010). Questions, Answers, and Knowledge- wh. Philosophical Studies, 147(3), 395-413. https://doi.org/10.1007/s11098-008-9288-z

Mathiesen, Kay (2011). Can Groups Be Epistemic Agents? In Hans Bernhard Schmid, Daniel Sirtes, and Marcel Weber (Eds.), Collective Epistemology (23-45). Transaction Books.

Meyer, John-Jules Ch. and Weibe van der Hoek (1995). Epistemic Logic for AI and Computer Science. Cambridge University Press. https://doi.org/10.1017/CBO9780511569852

Miller, Boaz (2015). Why Knowledge is the Property of a Community and Possibly None of Its Members. Philosophical Quarterly, 65(260), 417-441. https://doi.org/10.1093/pq/ pqv025

Muldoon, Ryan (2017) Diversity, Rationality, and the Division of Cognitive Labour, in Scientific Collaboration and Collective Knowledge: New Essays, Thomas Boyer-Kassem, 
Conor Mayo-Wilson, and Michael Weisberg (eds) New York: Oxford University Press pp. 78-94.

Nagel, Jennifer (2010). Knowledge Ascriptions and the Psychological Consequences of Thinking about Error. Philosophical Quarterly, 60(239), 286-306. https://doi. org/10.1111/j.1467-9213.2009.624.x

Noë, Alva (2005). Against Intellectualism. Analysis, 65 (4), 278-29o. https://doi.org/10.1093/ analys/65.4.278

Oliver, Alex and Timothy Smiley (2008). Is Plural Denotation Collective? Analysis, 68(297), 22-34. https://doi.org/10.1093/analys/68.1.22

Parent, Ted (2014). Knowing-Wh and Embedded Questions. Philosophy Compass, 9(2), 8195. https://doi.org/10.1111/phc3.12104

Pavese, Carlotta (2017). Know-How and Gradability. Philosophical Review, 126(3), 345383. https://doi.org/10.1215/00318108-3878493

Pavese, Carlotta (2015). Questions and the Structure of Answers. Unpublished manuscript.

Pritchard, Duncan (2010). Contextualism, Skepticism and Warranted Assertibility Manoeuvres. In Joseph Keim Campbell, Michael O'Rourke, and Harry Silverstein (Eds.), Knowledge and Skepticism (85-104). MIT Press. https://doi.org/10.7551/mitpress/9780262014083.003.0005

Quinton, Anthony (1976). Social Objects. Proceedings of the Aristotelian Society, 76, 1-27. https://doi.org/10.1093/aristotelian/76.1.1

Ritchie, Katherine (2016). Can Semantics Guide Ontology? Australasian Journal of Philosophy, 94(1), 24-41. https://doi.org/10.1080/00048402.2015.1045912

Ritchie, Katherine (in press). What We Can Do. Philosophical Studies.

Roberts, Craige (2004). Context in Dynamic Interpretation. In Laurence Horn and Gregory Wood (Eds.), The Handbook of Pragmatics (197-220). Blackwell. https://doi. org/10.1002/9780470756959.ch9

Roberts, Craige (2012). Information Structure in Discourse: Towards an Integrated Formal Theory of Pragmatics. Semantics and Pragmatics, 5(6), 1-69. Originally published in Jae-Hak Yoon and Andreas Kathol (Eds.) (1998), OSU Working Papers in Linguistics (Vol. 49). https://doi.org/10.3765/sp.5.6

Roberts, Craige (2018). Speech Acts in Discourse Context. In Daniel Fogal, Daniel Harris, and Matt Moss (Eds.), New Work on Speech Acts (31759). Oxford University Press. https://doi.org/10.1093/oso/9780198738831.003.0012

https://doi.org/10.1016/j.cogsys.2007.07.007

Ryle, Gilbert (1949). The Concept of Mind. Hutchinson.

Rysiew, Patrick (2007). Speaking of Knowing. Noûs, 41(4), 627-662. https://doi. org/10.1111/j.1468-0068.2007.00665.x

Scha, Remko (1981). Distributive, Collective, and Cumulative Quantification. In J Groenendijk, T Jansen, and M Stokhof (Eds.), Formal Methods in the Study of Language. Mathematical Centre Tracts (Nos. 135-6, 483-512). Mathematisch Centrum.

Schaffer, Jonathan (2007). Knowing the Answer. Philosophy and Phenomenological Research, 75(2), 383-403. https://doi.org/10.1111/j.1933-1592.2007.00081.x

Schaffer, Jonathan (2008). Knowledge in the Image of assertion. Philosophical Issues, 18(1), 1-19. https://doi.org/10.1111/j.1533-6077.2008.00134.x

Schmitt, Frederick, F. (1994). The Justification of Group Beliefs. In Frederick F. Schmitt 
(Ed.), Socializing Epistemology: The Social Dimensions of Knowledge (257-287). Rowman and Littlefield.

Schwarzschild, Roger (1996). Pluralities. Kluwer. https://doi.org/10.1007/978-94-0172704-4

Schwitzgebel, Eric (2002). A Phenomenal, Dispositional Account of Belief. Noûs, 36(2), 249-275. https://doi.org/10.1111/1468-0068.00370

Stanley, Jason (2005). Knowledge and Practical Interests. Oxford University Press. https:// doi.org/10.1093/0199288038.001.0001

Stanley, Jason (2011). Know How. Oxford University Press. https://doi.org/10.1093/acpro f:oso/9780199695362.001.0001

Stanley, Jason and Timothy Willliamson (2001). Knowing How. Journal of Philosophy, 98(8), 411-444. https://doi.org/10.2307/2678403

https://doi.org/10.1177/0306312712436547

Strevens, Michael (2003). The Role of the Priority Rule in Science. Journal of Philosophy, 10o(2), 55-79. https://doi.org/10.5840/jphil2003100224

Szabó, Zoltán Gendler (2017). Finding the Question. Philosophical Studies, 174(3), 779786. https://doi.org/10.1007/s11098-016-0756-6

Thagard, Paul (1997). Collaborative Knowledge. Noûs, 31(2), 242-261. https://doi. org/10.1111/0029-4624.00044

Tollefsen, Deborah (2007). Group Testimony. Social Epistemology, 21(3), 299-311. https:// doi.org/10.1080/02691720701674163

Tuomela, Raimo (2004). Group Knowledge Analyzed. Episteme, 1(2), 109-127. https://doi. org/10.3366/epi.2004.1.2.109

Turri, John (2011). The Express Knowledge Account of Assertion. Australasian Journal of Philosophy, 89(1), 37-45. https://doi.org/10.1080/00048401003660333

Wallis, Charles (2008). Consciousness, Context, and Know-How. Synthese, 160(1), 123153. https://doi.org/10.1007/s11229-006-9103-3

Weisberg, Michael (2010). New Approaches to the Division of Cognitive Labour. In P. D. Magnus and Jacob Busch (Eds.), New Waves in the Philosophy of Science (250-269). Palgrave. https://doi.org/10.1007/978-0-230-29719-7_13

Weisberg, Michael and Ryan Muldoon (2009). Epistemic Landscapes and the Division of Cognitive Labor. Philosophy of Science, 76(2), 225-252. https://doi.org/10.1086/644786

Williams, Alexander (2000). Adverbial Quantification over (Interrogative) Complements. Paper presented at West Coast Conference in Formal Linguistics 19. Available at http://ling.umd.edu/ alxndrw/Papers/AQ.pdf

Winsberg, Eric, Bryce Huebner and Rebecca Kukla (2014). Accountability and Values in Radically Collaborative Research. Studies in History and Philosophy of Science, Part A, 46, 16-23. https://doi.org/10.1016/j.shpsa.2013.11.007

Wray, K. Brad (2001). Collective Belief and Acceptance. Synthese, 129(3), 319-333. https:// doi.org/10.1023/A:1013148515033

Wray, K. Brad (2007). Who Has Scientific Knowledge? Social Epistemology, 21(3), 337-347. https://doi.org/10.1080/02691720701674288

Yablo, Steve (2010). Knowing about Things. Unpublished manuscript. Retrieved from http://www.mit.edu/ yablo/home/Papers_files/Knowing\%2oAbout\%2oThings.pdf

Yablo, Stephen (2014). Aboutness. Princeton University Press. https://doi.org/10.23943/ princeton/9780691144955.001.0001 
Yablo, Stephen (2016). Parts and Differences. Philosophical Studies, 173(1), 141-157. https:// doi.org/10.1007/s11098-014-0433-6

Zollman, Kevin J. S. (2010). The Epistemic Benefit of Transient Diversity. Erkenntnis, 72(1), 17-35. https://doi.org/10.1007/s10670-009-9194-6

Zwicky, Arnold M. and Jerrold M. Sadock (1975). Ambiguity Tests and How to Fail Them. Syntax and Semantics, 4, 1-36. 